\title{
Water-Based Separation of Urho's Oil Sands
}

\author{
Min $\mathrm{Li}^{1,2, a}$, Rongmei Geng ${ }^{2}$, Shuai Zhang ${ }^{2}$, Zheng Zhang ${ }^{2}$ \\ ${ }^{1}$ China University of Geosciences, Beijing 10083, China \\ ${ }^{2}$ China University of Petroleum, Beijing 102249, China \\ asony8071@sina.com
}

Keywords: Oil sands; Bitumen; Water-based separation; Influence factors.

Abstract. As the important unconventional energy source, oil sands have been paid more attention by the oil workers. The water-based separation method is widely applied to separate bitumen from oil sands. The water-based extraction bitumen has the advantages of large scale, extraction and separation without space restrictions, but the factors such as water temperature, and the ratio of water to oil sands can affect the recovery of bitumen. In this paper the influence factors of water-based separation of Urho's oil sands were studied. When the washing temperature was $85^{\circ} \mathrm{C}$, the ratio of water to oil sands was 2 , and the sodium hydroxide concentration was $0.1 \mathrm{wt} \%$, the recovery of bitumen was more than $85 \%$ in the experimental conditions.

\section{Introduction}

With the rapid development of economy, energy demand also gradually increases. Oil sands are a mixture of sand, water, clay and bitumen[1]. As the important unconventional energy sources, oil sands have been paid more attention by the oil workers. China has the fifth largest oil sand reserves in the world[2], and the quantity found in the Urho area of China is $8 \mathrm{~km}^{2}$. In order to enhance bitumen recovery, it is very important to study the influence of experimental conditions on the bitumen displacement from the sand and clay. The research results can provide the basis for separation of Urho's oil sands. The oil sands composition was analyzed, and meanwhile the influence factors, such as temperature, sodium hydroxide concentration, and the ratio of water to oil sands were researched in this paper.

\section{Experiments}

\section{Composition of Urho's oil sands}

The composition of oil sands was analyzed by Dean-Stark toluene extraction method[3], and the results were shown in Table 1.

Table 1 Composition of Urho's oil sands

\begin{tabular}{cccc}
\hline Composition & Bitumen & Water & Solids \\
\hline Mass fractions & $13.6 \mathrm{wt} \%$ & $1.8 \mathrm{wt} \%$ & $84.3 \mathrm{wt} \%$ \\
\hline
\end{tabular}

\section{Method}

Firstly add a certain amount of sodium hydroxide solution to $1000 \mathrm{~mL}$ beaker, put the beaker into a water bath pot, and pour slowly 300g oil sands into the beaker. Secondly stir with mixtures with an electric agitator at rotation speed of $160 \mathrm{r} / \mathrm{m}$ for 20 minute. When a large number of bitumen combining with bubbles rise to the surface of liquid, directly scrape the upper mixture of bitumen and bubble. Finally pour out the middle layer of liquid, and take the oil sands at the bottom to measure oil content. The oil content can be analyzed by the partition-infrared method. The calculation formula is expressed by Eq.(1) . In Eq.(1) $R$ is the recovery of bitumen, $A_{1}$ is oil content of initial oil sands, $A_{2}$ is solid content of initial oil sands, and $B_{1}$ is oil content of washed oil sands. 


$$
R=1-\frac{A_{2} \bullet B_{1}}{A_{1}\left(1-B_{1}\right)}
$$

\section{Results Analysis}

The water-based extraction bitumen has the advantages of large scale, extraction and separation without space restrictions, but the factors such as water temperature, and the ratio of water to oil sands can affect the recovery of bitumen[4,5,6]. In order to obtain the higher recovery, the optimal conditions must be determined by experiments.

The Influence of Washing Temperature On the Recovery of Bitumen. Suitable washing temperature in industrial production not only can control energy consumption costs, but also can guarantee higher recovery of bitumen.

When sodium hydroxide concentration was $0.1 \mathrm{wt} \%$ and the ratio of water to sand was 2 , the influence of washing temperature on the recovery of bitumen was studied. The result was shown in Fig. 1.

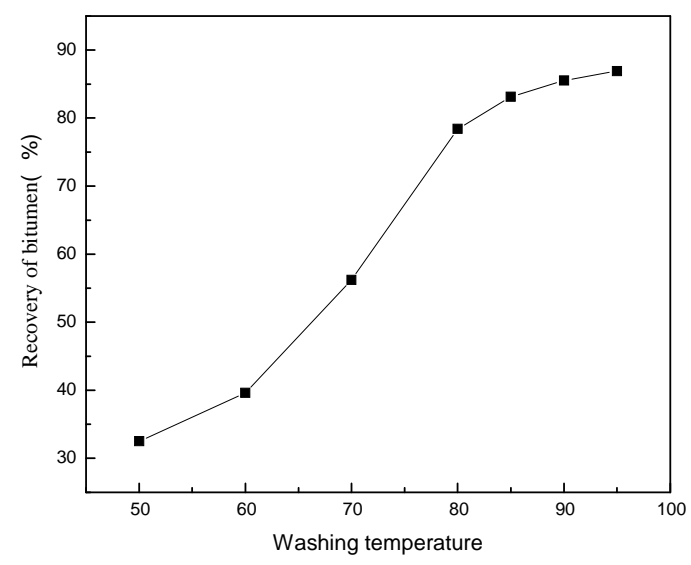

Fig. 1 Influence of washing temperature on the recovery of bitumen

With washing temperature increasing, the recovery of bitumen generally increased; When water temperature exceeded $85^{\circ} \mathrm{C}$, the recovery of bitumen increased slowly with the increase of temperature. When the washing temperature was $95^{\circ} \mathrm{C}$, the recovery of bitumen was $85 \%$, the highest.

The Influence of Sodium Hydroxide Concentration to The Recovery of Bitumen. The sodium hydroxide concentration also has a significant impact on the recovery of bitumen. Adding sodium hydroxide is mainly used to neutralize acid contained in pitch of oil sands and promote separation rate of the oil sands.

When the wash temperature was $85^{\circ} \mathrm{C}$ and the ratio of water to oil sands was 2 , the influence of sodium hydroxide concentration on the recovery of bitumen was studied. The result was shown in Fig. 2.

When $\mathrm{NaOH}$ concentration was $0.1 \mathrm{wt} \%$, the highest recovery of bitumen was achieved. When the concentration of $\mathrm{NaOH}$ was more than $0.1 \mathrm{wt} \%$, the bitumen, water and clay formed emulsion that resulted in lower recovery of bitumen. 


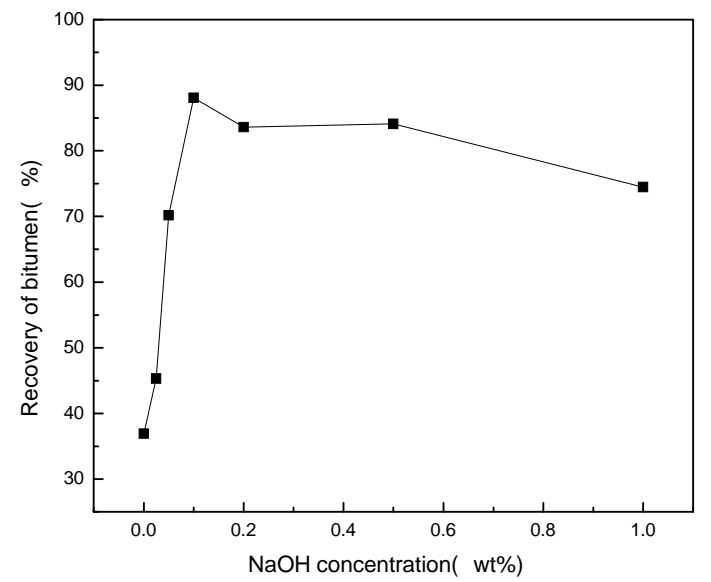

Fig. 2 Influence of $\mathrm{NaOH}$ concentration on the recovery of bitumen

The Influence of Ratio of Water to Oil Sands to The Recovery of Bitumen. The ratio of water to sand is the ratio of volume of water to quality of the oil sands. In the industrial production, the optimum ratio of water to oil sand not only saves water consumption but also obtains a higher recovery of bitumen.

When sodium hydroxide concentration was $0.1 \mathrm{wt} \%$ and the washing temperature was $85^{\circ} \mathrm{C}$, the influence of ratio of water to sand on the recovery of bitumen was studied. The result was shown in Fig. 3.

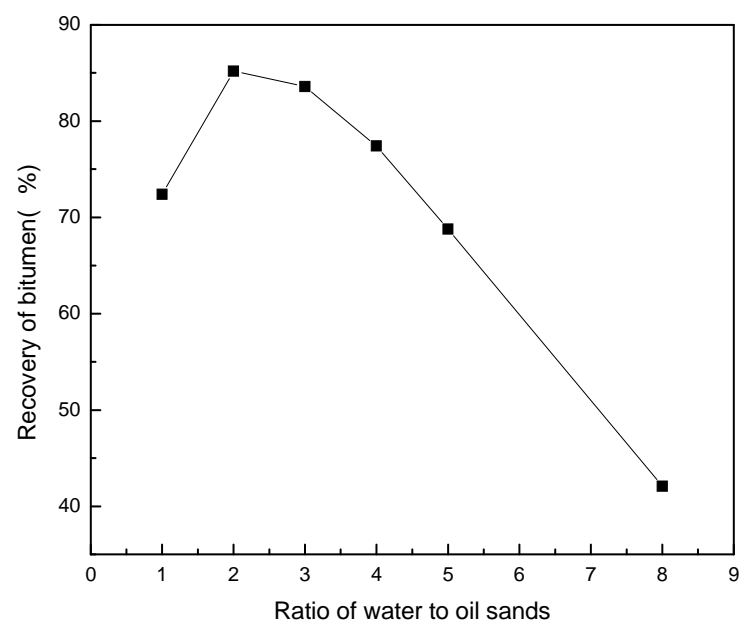

Fig. 3 Influence of the ratio of water to oil sands on the recovery of bitumen

With the increase of ratio of water to sand, recovery of bitumen firstly increased and then decreased. When the ratio of water to sand was 2, the recovery of bitumen was $85 \%$,the highest. When the ratio of water to sand was beyond 2 , the recovery of bitumen decreased.

\section{Conclusions}

The high washing temperature is beneficial to water-based separation of oil sands, but the high washing temperature will consume a large number of powers. Taken into consideration the recovery of bitumen and energy consumption, the optimum water temperature was $85^{\circ} \mathrm{C}$ in this paper.

The lower or higher sodium hydroxide concentration is unfavorable to separate the bitumen from the sand and clay. The optimum concentration of sodium hydroxide was $0.1 \mathrm{wt} \%$ in water-based extraction bitumen in this paper.

Water is high-value commodity. In order to save fresh water amount and wastewater treatment costs, the optimum ratio of water to oil sands is necessary. When the ratio of water to oil sands was 2 , the recovery of bitumen reached maximum in this paper. 
Under the optimal experimental conditions: the washing temperature was $85^{\circ} \mathrm{C}$, the ratio of water to oil sands was 2 , and the sodium hydroxide concentration was $0.1 \mathrm{wt} \%$, the recovery of bitumen was more than $85 \%$ with water-based separation of Urho's oil sands.

\section{References}

[1] Xiu-qiang XU, Hong-yan WANG, De-wen ZHENG:Liaoning Chemical Industry, 37(2008),p. 268.In Chinese

[2] Li LI:Petroleum \&Petrochemical today, 13(2005),p.28. In Chinese

[3] He-ming LUO, Xiao-ping YANG, Ming-shan DING:Journal of Xi'an Shiyou University( Natural Science Edition) , 30( 2015),p.67. In Chinese

[4] Ming-shan DING, Yan ZHANG, Juan LIU: AIChE Journal, 60(2014),p. 2985

[5] Masliyah J, Zhou Z J, Xu Z H:Canadian Journal of Chemical Engineering, 82(2004),p.628

[6] Hong-qiang YANG, Ming-shan DING, Bin HU:Chemical industry and engineering progress, 33(2014) ,p.2495. In Chinese 